\title{
A Patient with KL-6 Elevation with Anti-TNFa Who Could Receive Long-Term Use without Interstitial Pneumonia after Class Switch of Anti-TNFa
}

\author{
Takuya Masuda $^{a}$ Atsushi Yoshida $^{a}$ Fumiaki Ueno $^{a}$ Shintaro Hara ${ }^{a}$

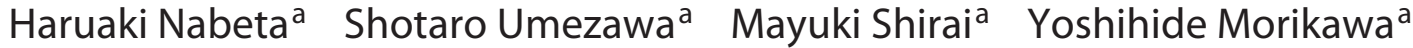 \\ Toshio Morizane $^{a}$ Yutaka Endo ${ }^{a}$ Toshifumi Hibi ${ }^{b}$ \\ ${ }^{a}$ Center for Gastroenterology and Inflammatory Bowel Disease, Ofuna Chuo Hospital, Kamakura, Japan; ${ }^{b}$ Center for \\ Advanced IBD Research and Treatment, Kitasato Institute Hospital, Tokyo, Japan
}

\section{Keywords}

Interstitial lung disease $\cdot$ anti-TNFa $\cdot$ Inflammatory bowel disease · Ulcerative colitis · Crohn's disease

\begin{abstract}
A 40-year-old man with refractory ulcerative colitis (UC) was treated with tumor necrosis factor a inhibitor (anti-TNFa), infliximab. One month later, the chest computed tomography and laboratory test showed noninfectious interstitial lung disease (ILD) and elevation of serum Krebs von den Lungen-6 (KL-6). Fortunately, ILD disappeared after the discontinuation with anti-TNFa. Two and a half years after his first UC treatment, he was treated again with another anti-TNFa, adalimumab, for relapse and he had a second ILD. This course suggested anti-TNFa induced ILD. The characteristics of anti-TNFa-induced ILD in inflammatory bowel disease (IBD) are not well understood. We summarized and investigated the characteristics of such patients based on a literature review including 15 cases. It suggested that anti-TNFainduced ILD in IBD might be rare and tends to have a better outcome compared with ILD in rheumatoid arthritis.
\end{abstract}

(c) 2019 S. Karger AG, Basel

\section{KARGER}

(c) 2019 S. Karger AG, Basel

E-Mail karger@karger.com

www.karger.com/iid

\section{Introduction}

The anti-tumor necrosis factor $\alpha$ inhibitor (anti$\mathrm{TNFa}$ ) is an effective therapy for patients with moderately severe ulcerative colitis (UC) and Crohn's disease patients who fail to respond to conventional therapy [1]. However, one of the adverse events of anti-TNFa, such as interstitial lung disease (ILD), could be a clinical problem. Little is known about anti-TNFa-induced ILD among inflammatory bowel disease (IBD) patients, although more cases about anti-TNFa-induced ILD were reported [2-4] in other disease fields. Here we present a rare Japanese case of UC with ILD. We describe the details of our patient and summarize past case reports in order to compare the characteristics, treatments, and clinical courses among IBD patients with ILD induced by anti-TNFa.

\section{Case Report}

A 40-year-old man with nonsmoker and no history of lung disease, was admitted to our hospital in November 2010 because of a moderately severe exacerbation of his 3-year history of UC. He had been taking azathioprine (AZA) $100 \mathrm{mg}$ /day and mesalazine $4 \mathrm{~g} /$ day since 2008 . He received 1 st infusion of anti-TNFa (infliximab 

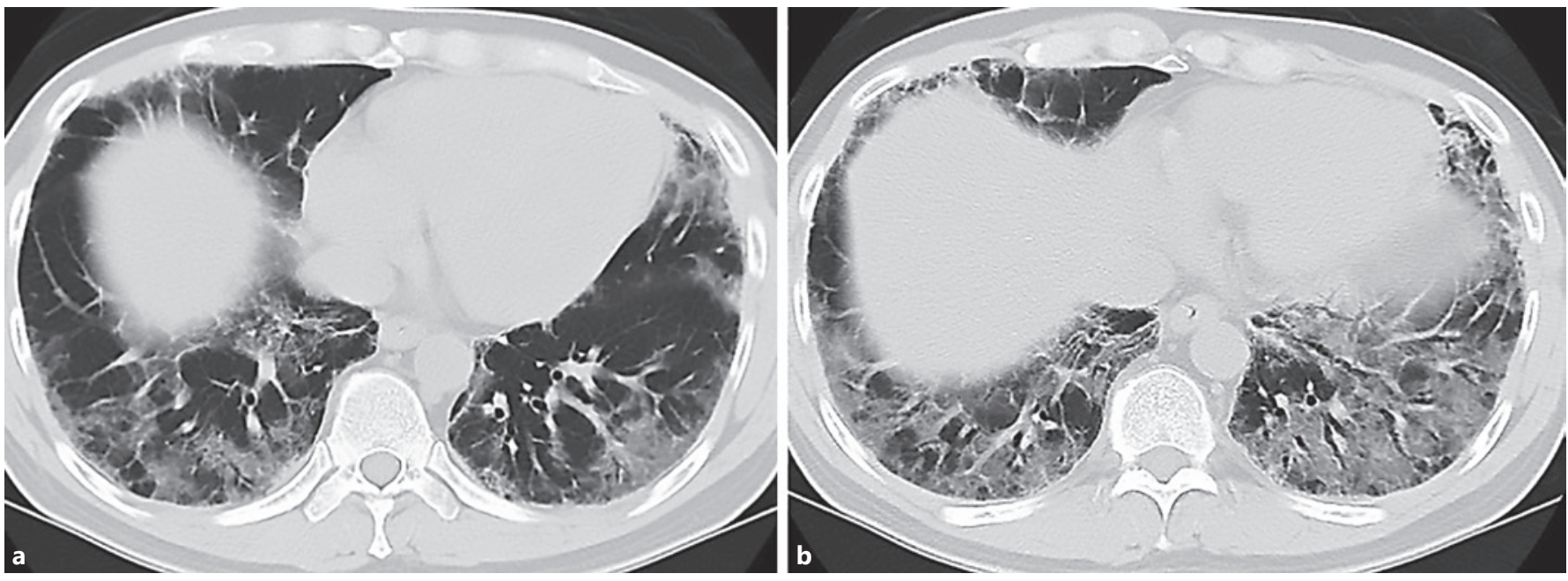

Fig. 1. Chest computed tomography after treatment with anti-TNFa showed diffuse ground-glass opacities with traction bronchiectasis in both middle lobes (a) and lower lobes (b).

[IFX]; $5 \mathrm{mg} / \mathrm{kg}$ ) and achieved clinical remission at the time of discharge.

However, 1 month after the 2 nd infusion of IFX $5 \mathrm{mg} / \mathrm{kg}$, he visited our hospital because of 2 weeks history of low-grade fever, nonproductive cough, and fatigue. Fine crackle was auscultated in bilateral lungs and pulse oximetry was $96 \%$ (room air). Laboratory test showed white blood cell count of $4,580 / \mathrm{mm}^{3}$, neutrophil count $2,480 / \mathrm{mm}^{3}$, hemoglobin $10.7 \mathrm{~g} / \mathrm{dL}$, hematocrit $34.8 \%$, serum LD $270 \mathrm{U} / \mathrm{L}$, serum albumin $4.2 \mathrm{~g} / \mathrm{dL}$, and C-reactive protein $2.15 \mathrm{mg} /$ dL. Chest X-ray and chest computed tomography (CT) showed non-segmental ground-glass opacity and traction bronchiectasis in bilateral lower lung fields. No findings of honeycomb shadows, mediastinal or both hilar lymphadenopathy, or pleural fluid in bilateral lung fields were seen (Fig. 1). Serum Krebs von den Lungen-6 (KL-6) levels were elevated at $1,820 \mathrm{U} / \mathrm{mL}$, while there was normal range of surfactant protein-D (SP-D) and negativity for serum $\beta$-D-glucan, anti-Mycoplasma pneumoniae antibody, PCR assay for Pneumocystis jirovecii of his sputum, and cytomegalovirus antigenemia assay. IFX was discontinued due to suspected drug-induced ILD. He was prescribed prednisolone (PSL) $30 \mathrm{mg} /$ day and tapering down into $0 \mathrm{mg} /$ day for 6 months. Fortunately, remission with maintenance therapy for 2 years has been carried out without exacerbation of UC. Serum KL-6 levels had returned to the normal range after the discontinuation with IFX. Chest CT showed the disappearance of ground-glass opacity.

He (42-year-old man) had relapse of UC and was admitted to the hospital 2 years after remission. Endoscopic appearance was severe UC (Mayo endoscopic subscore 3). He had been taking AZA $100 \mathrm{mg} /$ day and mesalazine $4 \mathrm{~g}$ /day since 2008; however, his clinical symptom became worse. Other types of anti-TNFa (adalimumab [ADA]) (160-80-40 mg) had started since December 2013. Once again, his serum KL-6 level elevated to 1,742 U/mL on March 2014 and kept a high level from 1,000 to 3,000 U/mL during treatment with ADA. But at this time, ADA was continued with carefully keeping consultation with a respiratory specialist, because he had desired to continue ADA, which maintained remission in UC, and ILD had not occurred in clinical symptom and CT image finding.

Two and a half years after ADA maintenance therapy, he (44-year-old man) had developed ILD again and laboratory test showed high level of serum KL-6 1,158 U/L and SP-D $159.9 \mathrm{ng} / \mathrm{dL}$. ILD was mildly active at this time and chest CT showed minor ground-glass opacity and linear opacities in bilateral lower lung fields. This ILD improved and serum KL- 6 and SP-D returned to the normal range promptly by PSL ( $30 \mathrm{mg} /$ day), even while continuing $\mathrm{ADA}$ administration and tapering down to PSL free. $\mathrm{He}$ has been continuing ADA for remission treatment of UC.

\section{Discussion}

This is the case report of not only developing druginduced ILD after induction of IFX and ADA, two different types of anti-TNFa, but also preceding the elevation of serum KL-6 level before the second onset of ILD after induction of ADA. Favorable complete remission of UC could be gained by anti-TNFa; however, a recent case report showed a fatal adverse effect in ILD induced by the drugs [5]. Although TNFa-induced ILD could occur among patients with various autoimmune diseases, there are few studies of anti-TNFa-induced ILD in IBD field. Thus, we summarized the previous case reports and studies of anti-TNFa agents inducing ILD among IBD patients [5-14].

The prevalence of respiratory adverse effects of IFX among 484 UC patients was reported to be 3.5\% (17/484), including 1 pneumonia, 1 tuberculosis, and 1 histoplasma 
Table 1. Summary of available IBD Cases with ILD induced by anti-TNFa

\begin{tabular}{|c|c|c|c|c|c|c|c|}
\hline Case & First author, year [ref.] & Age, years & Sex & $\begin{array}{l}\text { IBD } \\
\text { type }\end{array}$ & $\begin{array}{l}\text { Disease years } \\
\text { (IBD) }\end{array}$ & Pre-LD & Symptom \\
\hline 1 & Rofaiel, 2017 [5] & 53 & $\mathrm{~m}$ & UC & 11 & tuberculosis & severe dyspnea \\
\hline 3 & Lee, 2015 [7] & 58 & $\mathrm{~m}$ & $\mathrm{CD}$ & 0.3 & never & dyspnea \\
\hline 6 & Lee, 2015 [7] & 37 & $\mathrm{~m}$ & UC & 10 & never & dyspnea \\
\hline 7 & Lee, 2015 [7] & 39 & $\mathrm{f}$ & UC & 0.7 & never & dyspnea, fever \\
\hline 8 & Lee, 2015 [7] & 74 & $\mathrm{f}$ & UC & 5 & never & dyspnea, fever \\
\hline 9 & Kohno, 2015 [8] & 67 & $\mathrm{f}$ & $\mathrm{CD}$ & 6 & never & dry cough, chest pain \\
\hline 10 & Casanova, 2015 [9] & 59 & $\mathrm{f}$ & $\mathrm{CD}$ & 2 & smoker & dyspnea, cough, and fatigue \\
\hline 11 & Caccaro, 2013 [10] & 25 & $\mathrm{f}$ & $\mathrm{CD}$ & 9 & never & $\begin{array}{l}\text { shortness of breath and fa- } \\
\text { tigue }\end{array}$ \\
\hline 13 & Wiener, 2008 [12] & 63 & $\mathrm{f}$ & UC & 10 & smoker & dyspnea, dry cough \\
\hline 14 & Weatherhead, 2006 [13] & 22 & $\mathrm{f}$ & $\mathrm{CD}$ & 2 & N/A & cough, breathlessness \\
\hline 15 & Sen, $2012[14]$ & 29 & $\mathrm{f}$ & UC & 0.3 & asthma & dyspnea \\
\hline 16 & Our case & 40 & $\mathrm{~m}$ & UC & 3 & never & dry cough and fatigue \\
\hline Case & Anti-TNF & $\begin{array}{l}\text { ILD onset duration } \\
\text { after anti-TNFa } \\
\text { therapy }\end{array}$ & \multicolumn{2}{|c|}{ Other drugs } & \multicolumn{2}{|c|}{ Therapy for ILD } & Outcome \\
\hline 1 & infliximab & 16 weeks & \multicolumn{2}{|c|}{ 5-ASA, PSL } & \multicolumn{2}{|c|}{ continue anti-TNFa } & dead \\
\hline 2 & infliximab & 14 weeks & \multicolumn{2}{|c|}{ PSL, 5-ASA } & \multicolumn{2}{|c|}{ continue anti-TNFa } & resolved spontaneously \\
\hline 9 & infliximab $\rightarrow$ adalimumab & 14 weeks & \multicolumn{2}{|l|}{ AZA } & \multicolumn{2}{|c|}{ continue anti-TNFa, start steroid } & $\begin{array}{l}\text { improved after } 1 \text { week (CXR), } \\
\text { KL- } 6 \downarrow \text {, mucosal healing }\end{array}$ \\
\hline 10 & adalimumab & 4 weeks & \multicolumn{2}{|l|}{ AZA } & \multicolumn{2}{|c|}{ stop anti-TNFa, start steroid } & $\begin{array}{l}\text { normalization of spirometry } \\
\text { after } 12 \text { weeks }\end{array}$ \\
\hline 11 & adalimumab $\rightarrow$ infliximab & 16 weeks & \multicolumn{2}{|c|}{ 5-ASA, PSL, AZA } & \multicolumn{2}{|c|}{ stop anti-TNFa, start steroid } & improved after 10 weeks (CT) \\
\hline 12 & adalimumab & 40 weeks & \multicolumn{2}{|c|}{ PSL, MTX } & \multicolumn{2}{|c|}{ stop anti-TNFa, start steroid } & $\begin{array}{l}\text { clinical and CXR improve- } \\
\text { ment within } 8 \text { weeks and } \\
\text { restart methotrexate }\end{array}$ \\
\hline 13 & infliximab & 24 weeks & \multicolumn{2}{|c|}{ PSL, 5-ASA, AZA } & \multicolumn{2}{|l|}{ start steroid } & $\begin{array}{l}\text { clinical improvement within } 6 \\
\text { weeks }\end{array}$ \\
\hline 14 & infliximab & 2 weeks & 5 -AS & $\mathrm{ZA}$ & stop anti-TNI & tart steroid & $\begin{array}{l}\text { normalization of spirometry } \\
\text { after } 2 \text { weeks }\end{array}$ \\
\hline 15 & infliximab & 2 weeks & none & & stop anti-TNI & tart steroid & improved after 12 weeks (CT) \\
\hline 16 & infliximab $\rightarrow$ adalimumab & 6 weeks & 5-AS & $\mathrm{ZA}$ & $\begin{array}{l}\text { 1. stop anti-T } \\
\text { 2. continue ar }\end{array}$ & $\begin{array}{l}\text {, start steroid } \\
\mathrm{NFa} \text {, start steroid }\end{array}$ & $\begin{array}{l}\text { improved after } 24 \text { weeks } \\
\text { (CXR) } \\
\text { improvde after } 8 \text { weeks (CT) }\end{array}$ \\
\hline
\end{tabular}

Anti-TNFa-Induced Interstitial

Pneumonia with KL-6 Elevation
Inflamm Intest Dis 2019;4:35-40

DOI: $10.1159 / 000497778$ 
Table 2. The biologic therapy with elevated KL-6 values and the progression of ILD

\begin{tabular}{|c|c|c|}
\hline First author, year [ref.] & Biologic therapy with elevated KL-6 & $\begin{array}{l}\text { Progression of ILD with abnor- } \\
\text { mal KL- } 6 \text { values }\end{array}$ \\
\hline Takahashi, 2014 [29] & infliximab $11.2 \%$, etanercept $4.4 \%$, adalimumab $22.2 \%$, tocilizumab $0 \%$ on RA & anti-TNFa ILD events $20.0 \%$ \\
\hline Harigai, 2013 [30] & infliximab $15.6 \%$, certolizumab pegol $7.8 \%$, golimumab $1.8 \%$ on RA & no apparent ILD \\
\hline Takamura, 2013 [31] & infliximab, etanercept, adalimumab, and tocilizumab $17.9 \%$ on RA & no apparent ILD \\
\hline Koiwa, $2012[32]$ & adalimumab $10.3 \%$ on RA & no apparent ILD \\
\hline Hayashi, 2017 [27] & infliximab or adalimumab $55 \%$ on psoriasis & no apparent ILD \\
\hline
\end{tabular}

(dead) from the result of ACT trial [15]. However, noninfectious lung disease, such as ILD, might be a rare adverse effect among UC patients using anti-TNFa because neither noninfectious ILD nor elevation of KL-6 were reported among these patients, while the prevalence of antiTNF $\alpha$-induced ILD is reported to be $0.5-0.6 \%$ in rheumatoid arthritis (RA) [16].

The demographic and clinical characteristics of 16 IBD patients including our patient are summarized in Table 1 . The average age was $49 \pm 15$ years (mean \pm SD), and 10 of 16 patients $(63 \%)$ were female. The tendency of clinical features was a mature woman in the early period (5.4 \pm 4.3 years) of IBD, regardless of any types of IBD (UC9:CD7). None of the association was seen with the history of previous lung disease such as smoking or autoimmune disease, which was not seen in our patient. However, he rapidly developed anti-TNFa-induced ILD so that it is difficult to predict appearance of the ILD from their history. The remarkable characteristics of clinical symptoms were dyspnea (13/16), cough (9/16), and fever $(4 / 16)$. Thus, these clinical symptoms are important to make an early diagnosis of anti-TNFa agent-induced ILD (Table 1).

In IBD patients with noninfectious ILD, IFX was more reported (IFX:ADA, 10:5) in the past cases (Table 1). Our patient developed ILD 1 month after IFX (chimeric antibody) induction. Previously, lung toxicity by ADA (complete human antibody) was controversial. However, our patient recurred with ILD caused by ADA after 2.5 years. According to the past case report [17], as example of the case of ADA-induced ILD in RA, ADA could be a risk of ILD.

IBD patients have a tendency to shorter periods of developing ILD after induction of anti-TNFa than other autoimmune diseases because the average $( \pm \mathrm{SD})$ was $13.0 \pm$ 10.4 weeks among IBD patients and $26.3 \pm 5.3$ weeks among patients with other autoimmune diseases [3] (Table 1), whereas our patient had 6 weeks to the first onset and 2.5 years to the second onset of ILD.
5-ASA or AZA as combined drugs of anti-TNFa were used at a high rate (Table 1). However, these drugs or IBD itself were known to cause ILD, especially lymphocyte infiltration or fibrosis on interstitial tissue of lung [18]. Remarkably, almost all these case series did not develop ILD until induction of anti-TNFa agent, despite long-term administration of 5-ASA or AZA, and this fact indicates that anti-TNFa might have some pathogenic effect of developing IDL or exacerbating latent ILD lesions caused by other drugs of IBD or IBD itself. In our patient, ILD was not recurrent during off-terms of anti-TNFa agent with the use of 5-ASA and AZA.

The mechanism of anti-TNFa-induced ILD is still unclear $[19,20]$. Past studies showed that anti-TNFa improves ILD as well as exacerbates it among patients with various autoimmune disease $[2,21]$, whereas recent studies showed a part of the mechanisms of how anti-TNFa could promote automatic inflammatory response. Some basic research revealed that anti-TNFa antibody could inhibit membrane TNF receptor 2 , which is needed for inducing apoptosis of activated inflammatory cells [22], and activate TNF receptor 2-positive pathogenic T cells through anti-TNFa antibody and TNF receptor 2 complex [23]. These data may explain why both IFX and ADA, two different types of anti-TNFa, caused ILD in our patient.

Elevation of KL-6 during occurrence or recurrence of ILD induced by two different anti-TNF $\alpha$ was remarkable in our patient. KL- 6 is one of the common ILD serum markers and exists on the membrane of type 2 alveolar epithelium, and elevation of serum KL-6 indicates destruction or reproduction of type 2 alveolar epithelium, or increased permeability of alveolar capillary barrier from any cause [24].

One study showed that a serum KL-6 level of over $2,750 \mathrm{U} / \mathrm{mL}$ was associated with poor outcome among patients with ILD due to idiopathic or collagen disease [25]. Moreover, a study of 30 cases of drug-induced ILD due to various drugs (excluding anti-TNFa) showed that
38

Inflamm Intest Dis 2019;4:35-40 DOI: $10.1159 / 000497778$
Masuda et al. 
elevation of KL-6 was associated with more serious types of diffuse alveolar damage pattern or chronic interstitial pneumonia pattern, and not with mild type of bronchiolitis obliterans organizing pneumonia/eosinophilic pneumonia or hypersensitivity pneumonitis pattern [26]. According to these data, a high level of serum KL-6 might predict poor outcome in patients with ILD.

However, $52 \%$ of psoriasis patients treated with IFX or ADA experienced increase of serum KL-6 without developing ILD. Furthermore, spontaneous decrease in serum KL-6 was seen among some psoriasis patients treated with anti-TNFa $[27,28]$. In some RA patient, serum KL-6 elevated during use of anti-TNFa and decreased after withdrawing its agent [29-32] (Table 2). According to the clinical trial of anti-TNFa in RA, $11.2 \%, 4.4 \%, 22.2 \%$, and $0 \%$ of RA participants treated with IFX, etanercept, ADA, and tocilizumab, respectively, experienced elevation of serum KL-6 ( $\geq 500 \mathrm{U} / \mathrm{mL})$ [29]. Similar findings were seen in trials with IFX (15.6\%), certolizumab pegol (7.8\%), and golimumab (1.8\%) [30], and the progression of ILD with abnormal KL-6 value was very low. KL-6 elevation tends to be lower in human or humanized monoclonal antibody (golimumab, tocilizumab) than in chimeric antibody (IFX) (Table 2). In our case, a high level of serum KL-6 was seen during the first ILD and preceded the onset of the second ILD. Hence, elevation of serum KL-6 during induction of anti-TNF $\alpha$ could be useful for diagnosis or prediction of ILD but not necessarily for prediction of poor outcome.

In most IBD cases, ILD was treated with steroids and withdrawing anti-TNFa agents. The average period of improving ILD was $8.2 \pm 10.5$ weeks $( \pm$ SD) (Table 1 ). However, some cases tried to continue ADA with combination of steroid in the second onset of ILD, like in our case $[7,10-14,17]$.

The association with mortality risk due to anti-TNFa agent-induced ILD seems to be old age (above 65 years old), frequent use of immunosuppressive drugs, and rapid diagnosis of ILD [3]. Regarding severity or lethality, IBD cases with anti-TNFa agent-induced ILD tended to have better outcome than various autoimmune diseases.
Only one patient died during rapid induction of IFX in UC [5], while 15 of 52 RA patients with ILD [3]. Hence, careful investigation of ILD symptoms such as dyspnea or dry cough and rapid treatment are important when starting anti-TNFa in IBD patients. Our case succeeded to continue UC remission maintenance without withdrawing ADA by temporally combining PSL.

\section{Conclusion}

We reported a rare UC case of anti-TNFa-induced ILD and summarized the literature and our case including 16 IBD case reports. Clinicians should recognize the risk of anti-TNFa-induced ILD, which tends to have a better outcome by stopping anti-TNFa or using steroid. Elevation of serum KL- 6 during anti-TNFa treatment could be useful to remind the risk of developing ILD but not necessarily for prediction of poor outcome.

\section{Statement of Ethics}

The study was performed in accordance with the ethics guidelines in Japan. This report did not need to be approved by the institution's ethics committee. Patient's informed consent was obtained.

\section{Disclosure Statement}

There is no conflict of interest.

\section{Author Contributions}

A. Yoshida, F. Ueno designed the study. The data were collected by T. Masuda, A. Yoshida. T. Masuda, A. Yoshida, T. Morizane analyzed the data. T. Masuda, A. Yoshida drafted the manuscript. T. Masuda, A. Yoshida, S. Hara, H. Nabeta, S. Umezawa, M. Shirai, Y. Morikawa, Y. Endo interpreted the data, and T. Hibi made critical revisions to the manuscript. All authors reviewed and approved the final version of manuscript.

\section{References}

Anti-TNFa-Induced Interstitial

Pneumonia with KL-6 Elevation
1 Ford AC, Sandborn WJ, Khan KJ, Hanauer SB, Talley NJ, Moayyedi P. Efficacy of biological therapies in inflammatory bowel disease: systematic review and meta-analysis. Am J Gastroenterol. 2011 Apr;106(4):644-59.

2 Khasnis AA, Calabrese LH. Tumor necrosis factor inhibitors and lung disease: a paradox of efficacy and risk. Semin Arthritis Rheum. 2010 Oct;40(2):147-63.
3 Perez-Alvarez R, Perez-de-Lis M, DiazLagares C, Pego-Reigosa JM, Retamozo S, Bove A, et al. Interstitial lung disease induced or exacerbated by TNF-targeted therapies: analysis of 122 cases. Semin Arthritis Rheum. 2011 Oct;41(2):256-64. 
4 Hagiwara K, Sato T, Takagi-Kobayashi S, Hasegawa S, Shigihara N, Akiyama O. Acute exacerbation of preexisting interstitial lung disease after administration of etanercept for rheumatoid arthritis. J Rheumatol. 2007 May; 34(5):1151-4.

5 Rofaiel R, Kohli S, Mura M, HosseiniMoghaddam SM. A 53-year-old man with dyspnoea, respiratory failure, consistent with infliximab-induced acute interstitial pneumonitis after an accelerated induction dosing schedule. BMJ Case Rep. 2017 May;2017:12.

6 Numakura T, Tamada T, Nara M, Muramatsu S, Murakami K, Kikuchi T, et al. Simultaneous development of sarcoidosis and cutaneous vasculitis in a patient with refractory Crohn's disease during infliximab therapy. BMC Pulm Med. 2016 Feb;16(1):30.

7 Lee HS, Jo KW, Shim TS, Song JW, Lee HJ, Hwang SW, et al. Six Cases of Lung Injury Following Anti-tumour Necrosis Factor Therapy for Inflammatory Bowel Disease. J Crohn's Colitis. 2015 Nov;9(11):1053-7.

8 Kohno H, Okada H, Hiraoka S, Tanaka T. [A case of asymptomatic Sjögren's syndrome who developed interstitial pneumonia during monoclonal antibody therapy of Crohn's disease]. Nihon Shokakibyo Gakkai Zasshi. 2015 Jul;112(7):1326-33.

9 Casanova MJ, Chaparro M, Valenzuela C, Cisneros C, Gisbert JP. Adalimumab-induced interstitial pneumonia in a patient with Crohn's disease. World J Gastroenterol. 2015 Feb;21(7):2260-2.

10 Caccaro R, Savarino E, D'Incà R, Sturniolo GC. Noninfectious interstitial lung disease during infliximab therapy: case report and literature review. World J Gastroenterol. 2013 Aug;19(32):5377-80.

11 Reid JD, Bressler B, English J. A case of adalimumab-induced pneumonitis in a 45 -yearold man with Crohn's disease. Can Respir J. 2011 Sep-Oct; 18(5):262-4.

12 Wiener CM, Muse VV, Mark EJ. Case records of the Massachusetts General Hospital. Case 33-2008. A 63-year-old woman with dyspnea on exertion. N Engl J Med. 2008 Oct;359(17): 1823-32.

13 Weatherhead M, Masson S, Bourke SJ, Gunn MC, Burns GP. Interstitial pneumonitis after infliximab therapy for Crohn's disease. Inflamm Bowel Dis. 2006 May;12(5):427-8.
14 Sen S, Peltz C, Jordan K, Boes TJ. Infliximabinduced nonspecific interstitial pneumonia. Am J Med Sci. 2012 Jul;344(1):75-8.

15 Rutgeerts P, Sandborn WJ, Feagan BG, Reinisch W, Olson A, Johanns J, et al. Infliximab for induction and maintenance therapy for ulcerative colitis. N Engl J Med. 2005 Dec; 353(23):2462-76.

16 Takeuchi T, Tatsuki Y, Nogami Y, Ishiguro N, Tanaka Y, Yamanaka H, et al. Postmarketing surveillance of the safety profile of infliximab in 5000 Japanese patients with rheumatoid arthritis. Ann Rheum Dis. 2008 Feb;67(2):18994.

17 Komiya K, Ishii H, Fujita N, Oka H, Iwata A, Sonoda $\mathrm{H}$, et al. Adalimumab-induced interstitial pneumonia with an improvement of pre-existing rheumatoid arthritis-associated lung involvement. Intern Med. 2011;50(7): 749-51.

18 Majewski S, Piotrowski W. Pulmonary manifestations of inflammatory bowel disease. Arch Med Sci. 2015 Dec;11(6):1179-88.

19 Hilary C. Cain: Drug-induced pulmonarydisease due to nonchemotherapeutic agents. Fishman's pulmonary diseases and disorders fifth edition 2015; p945-992.

20 Kalliolias GD, Ivashkiv LB. TNF biology, pathogenic mechanisms and emerging therapeutic strategies. Nat Rev Rheumatol. 2016 Jan;12(1):49-62.

21 Nakashita T, Ando K, Kaneko N, Takahashi $\mathrm{K}$, Motojima S. Potential risk of TNF inhibitors on the progression of interstitial lung disease in patients with rheumatoid arthritis. BMJ Open. 2014 Aug;4(8):e005615.

22 Blüml S, Binder NB, Niederreiter B, Polzer K, Hayer S, Tauber S, et al. Antiinflammatory effects of tumor necrosis factor on hematopoietic cells in a murine model of erosive arthritis. Arthritis Rheum. 2010 Jun;62(6):1608-19.

23 McCann FE, Perocheau DP, Ruspi G, Blazek K, Davies ML, Feldmann M, et al. Selective tumor necrosis factor receptor I blockade is antiinflammatory and reveals immunoregulatory role of tumor necrosis factor receptor II in collagen-induced arthritis. Arthritis Rheumatol. 2014 Oct;66(10):2728-38.

24 Ishikawa N, Hattori N, Yokoyama A, Kohno N. Utility of KL-6/MUC1 in the clinical management of interstitial lung diseases. Respir Investig. 2012 Mar;50(1):3-13.
25 Satoh H, Kurishima K, Ishikawa H, Ohtsuka M. Increased levels of KL-6 and subsequent mortality in patients with interstitial lung diseases. J Intern Med. 2006 Nov;260(5):429-34.

26 Ohnishi H, Yokoyama A, Yasuhara Y, Watanabe A, Naka T, Hamada $\mathrm{H}$, et al. Circulating KL-6 levels in patients with drug induced pneumonitis. Thorax. 2003 Oct;58(10):8725.

27 Hayashi M, Yanaba K, Umezawa Y, Asahina A, Nakagawa H. Impact of anti-tumor necrosis factor- $\alpha$ agents on serum levels of KL-6 and surfactant protein- $\mathrm{D}$ in patients with psoriasis. J Dermatol. 2017 Sep;44(9):1063-6.

28 Higashi Y, Tada K, Shimokawa M, Kawai K, Kanekura T. Elevation of serum KL-6 in patients with psoriasis treated with anti-tumour necrosis factor- $\alpha$ therapy. Clin Exp Dermatol. 2016 Jan;41(1):88-90.

29 Takahashi K, Nakamura H, Takenouchi K, Iizawa N, Koiwa M, Sato A, et al. Serum KL-6 elevation and possible pulmonary involvement in patients with rheumatoid arthritis treated with biological agents. J Nippon Med Sch. 2014;81(6):364-71

30 Harigai M, Takamura A, Atsumi T, Dohi M, Hirata S, Kameda H, et al. Elevation of KL-6 serum levels in clinical trials of tumor necrosis factor inhibitors in patients with rheumatoid arthritis: a report from the Japan College of Rheumatology Ad Hoc Committee for Safety of Biological DMARDs. Mod Rheumatol. 2013 Mar;23(2):284-96.

31 Takamura A, Hirata S, Nagasawa H, Kameda $\mathrm{H}$, Seto $\mathrm{Y}$, Atsumi $\mathrm{T}$, et al. A retrospective study of serum KL-6 levels during treatment with biological disease-modifying antirheumatic drugs in rheumatoid arthritis patients: a report from the Ad Hoc Committee for Safety of Biological DMARDs of the Japan College of Rheumatology. Mod Rheumatol. 2013 Mar;23(2):297-303.

32 Koiwa M, Goto S, Takenouchi K, Takahasi K, Kamada T, Nakamura H. Elevation of serum KL-6 levels in 3 patients with rheumatoid arthritis treated with adalimumab. Mod Rheumatol. 2012 Feb;22(1):147-51. 